
ra 25: 291-295.

\title{
Efeito de injúrias mecânicas na qualidade de abobrinhas armazenadas em condição ambiente
}

\author{
Maria Fernanda Berlingieri Durigan'; Ben-Hur Mattiuz \\ UNESP-FCAV Jaboticabal-SP; ${ }^{1}$ Doutoranda; mfbdurigan@yahoo.com.br; benhur@fcav.unesp.br
}

\begin{abstract}
RESUMO
Foram avaliados os efeitos de diferentes injúrias mecânicas na qualidade de abobrinhas verdes cv. caipira, em três tipos de lesões: por impacto, compressão e corte. No impacto os frutos foram soltos em queda livre de uma altura de 1,60 m duas vezes (uma batida de cada lado do fruto), a compressão foi feito pela pressão de um peso de $58,8 \mathrm{~N}$ por 1 hora e o corte $(6 \mathrm{~cm}$ de comprimento e $2 \mathrm{~mm}$ de profundidade, em triplicata em 2 lados dos frutos) efetuado com uma faca apropriada. Após esses tratamentos, os frutos injuriados e os do controle (intactos) foram armazenados em condições de ambiente $\left(25^{\circ} \mathrm{C}, 65 \% \mathrm{UR}\right)$. As avaliações foram feitas a cada 3 dias, determinando-se atividade respiratória, aparência, perda de massa, $\mathrm{pH}$, teores de sólidos solúveis, acidez titulável, ácido ascórbico, amido e carboidratos solúveis. Durante o período de armazenamento, de 15 dias, as lesões mostraram-se prejudiciais à qualidade, afetando distintamente os parâmetros químicos, a aparência, e diminuindo os dias de possível comercialização dos frutos, em especial naqueles submetidos ao corte e ao impacto. Estas injúrias também ocasionaram maior atividade respiratória dos frutos. A perda de massa fresca foi agravada quando os frutos foram submetidos ao corte. A injúria por impacto e por corte foram as mais prejudiciais para a qualidade das abobrinhas 'Caipira'.
\end{abstract}

Palavras-chave: Cucurbita moschata, pós-colheita, compressão, impacto, corte.

\begin{abstract}
Effect of mechanical injuries on the quality of squash stored at room temperature

The effects of different mechanical injuries were evaluated on green squash cv. Caipira, such as impact, compression and cut. The impact injury was done by dropping the fruit from a height of 1.60 $\mathrm{m}$ on a hard and plain surface. Compression was made by pressing a weight of $58.8 \mathrm{~N}$ on the squash fruit for 1 hour and the cut was done by using a knife to make wounds ( $2 \mathrm{~mm}$ deep and $6 \mathrm{~cm}$ length) three times in both sides of the fruits. Injuried and intact fruits were stored at room temperature $\left(25^{\circ} \mathrm{C}, 65 \% \mathrm{RH}\right)$. Evaluations were done every three days, measuring the respiratory activity, appearance, loss of fresh mass, $\mathrm{pH}$, content of soluble solids, titratable acidity, ascorbic acid, starch and soluble carbohydrates. During the 15-day storage the injured fruits showed the worst quality, affecting the chemical parameters, the appearance and reduced the shelf life, mainly of those fruits submitted to cut and impact injuries. These injuries also increased the respiratory activity. Loss of weight was increased when the fruit were submitted to cuts. Impact and the cut injuries on immature fruits of squashes caused higher losses.
\end{abstract}

Keywords: Cucurbita moschata, postharvest, compression, impact, cut.

(Recebido para publicação em 7 de junho de 2006; aceito em 22 de maio de 2007)

$\mathrm{N}$ o grupo de abóboras colhidas imaturas, a abobrinha verde destacase por ser um fruto mais bem aceito que a abobrinha-italiana, em mercados interioranos. Um bom exemplo é a tradicional cultivar nacional Menina Brasileira, cujos frutos apresentam "pescoço". Há mais de uma cultivar dessa seleção, todas conservando a característica de resistência a viroses e rama longa. Há também as abóboras denominadas "caipira", cujos frutos são colhidos imaturos, apresentam a forma alongada, sem "pescoço", com cerca de $20 \mathrm{~cm}$ de comprimento. Estas são muito apreciadas em determinados mercados, como o de Goiânia e o de Uberlândia (Filgueira, 2003).

Segundo o autor supracitado, as abobrinhas verdes devem ser colhidas aos 60-80 dias após a semeadura, quando apresentem cerca de $30 \mathrm{~cm}$ de comprimento. Geralmente são comercializados em caixas tipos " $\mathrm{K}$ ", com capacidade de $22 \mathrm{~kg}$. Este tipo de embalagem, assim como o armazenamento a granel, leva os frutos a apresentarem severas lesões por compressão e corte, dado o mau arranjo nas caixas e amontoamento a granel.

Grande parte das perdas pós-colheita é determinada por ocasião da entrega para distribuição do produto proveniente do campo e são resultantes, basicamente, de manuseios excessivos e acondicionamentos inadequados. Estes problemas são agravados pelo mau estado de conservação das estradas, o que aumenta a trepidação e, conseqüentemente, as injúrias mecânicas. Reduções nessas perdas são, provavelmente, mais importantes que aumentos na produção, uma vez que os custos e a energia envolvidos durante o processo produtivo são totalmente desperdiçados, à medida que o produto é perdido mais próximo do ponto de consumo (Chau, 1997).

As maiores perdas durante o transporte são devidas a danos mecânicos, o que é acentuado pela falta de proteção que deveria ser dada pelas embalagens. Batidas ou pancadas e cortes podem levar a infecções microbianas, particularmente quando o tempo de armazenamento é longo (Medlicott, 1997). À medida que os frutos sofrem injúrias, também ocorre aumento na liberação de $\mathrm{CO}_{2}$, pois as células próximas ao local danificado passam a respirar mais intensamente. Com esse aumento na taxa respiratória há evolução na concentração de etileno, acelerando o processo de amadurecimento e senescência, diminuindo a qualidade e a vida útil do fruto (Hyodo et al., 1993; Ishii et al., 1993; Chitarra \& Chitarra, 1990). O objetivo deste trabalho foi ava- 

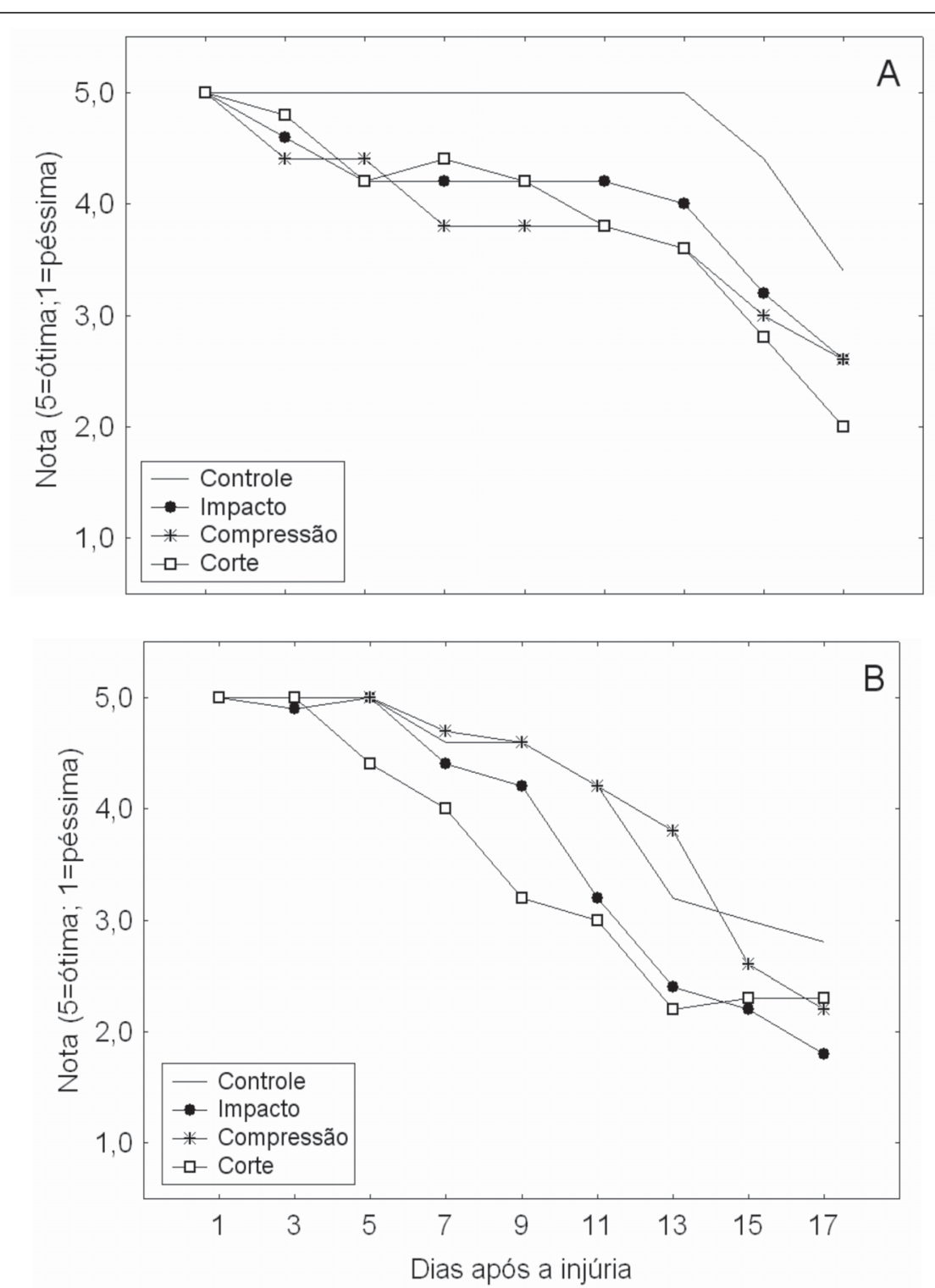

Figura 1. Aparência externa (A) e interna (B) de abobrinhas 'Caipira', submetidas a diferentes injúrias mecânicas e armazenadas a $25^{\circ} \mathrm{C}$ e $65 \%$ UR (external appearance (A) and internal (B) of green squash 'Caipira', submitted to various mechanical injuries and stored under $25^{\circ} \mathrm{C}$ and $65 \%$ UR). Jaboticabal, UNESP, 2005.

liar os efeitos de diferentes injúrias mecânicas na qualidade de abobrinhas verdes 'Caipira'.

\section{MATERIAL E MÉTODOS}

Abobrinhas verdes do tipo 'Caipira' foram colhidas no estádio de maturação indicado para comercialização, cujas características são: peso médio 790 g, casca verde-claro, lisa e aparentemente imaturo, ou seja, suculento e macio. $\mathrm{O}$ pedúnculo foi cortado com faca afiada, deixando-se uma porção com aproximadamente $2 \mathrm{~cm}$ aderida ao fruto, para pre-
1,60 m sobre uma superfície maciça, plana e rígida. Cada fruto sofreu dois impactos, nos lados opostos de sua linha equatorial. Na injúria por compressão, os frutos foram colocados sobre uma superfície plana e sob a ação de um peso de 58,8 N, durante 1 hora. Na injúria por corte, os frutos foram submetidos a três incisões com $6 \mathrm{~cm}$ de comprimento por $2 \mathrm{~mm}$ de profundidade, feitos com lâminas adaptadas a esta função, no sentido longitudinal e em ambos os lados do fruto. Frutos não injuriados compuseram o tratamento controle. As áreas lesionadas foram demarcadas e os frutos armazenados sob condições de ambiente $\left(25 \pm 1^{\circ} \mathrm{C}\right.$ e $65 \pm 5 \%$ UR).

Este experimento foi conduzido em delineamento inteiramente casualizado, num esquema fatorial composto por três fatores: tipo de injúria; local da injúria (no mesmo fruto foram consideradas as regiões injuriadas e as regiões não injuriadas) e dias de armazenamento. Foram utilizadas três repetições com três frutos cada para a determinação de $\mathrm{CO}_{2}$ e para as análises químicas, e dez para as determinações de coloração e de massa fresca.

A perda de massa fresca foi obtida através da pesagem dos frutos em balança eletrônica "Marte", sensibilidade de 0,02 g. As avaliações foram feitas a cada 3 dias, analisando-se as evoluções na massa fresca, na coloração e na aparência externa em um grupo fixo de frutos e as análises químicas e de aparência interna através de análises destrutivas. A aparência interna e externa foi avaliada mediante a atribuição de notas. Nota 5 (ótima) foi atribuída aos frutos em perfeitas condições de comercialização, considerando casca verde-claro, lisa e brilhante, aparentemente imaturo, suculento e macio, ausência de podridão, e polpa clara e macia. Nota 4 (boa) foi atribuída aos frutos em boas condições de comercialização, porém com casca verde mais escura, menos brilhante, sem podridões e polpa clara e macia. Nota 3 (regular) para os frutos com casca escura, enrugada, levemente murcho, frutos endurecidos ou moles, sem podridões e polpa característica. A nota 2 (ruim) foi atribuída a frutos com casca escura, enrugada, muito murcho, frutos endu- 
Tabela 1. Médias de coloração e da composição química de abobrinhas verdes 'Caipira', submetidas a diferentes injúrias mecânicas e armazenadas a $25^{\circ} \mathrm{C}$ e $65 \%$ UR (means of coloration and chemical composition of green squash 'caipira', submitted to mechanical injuries and stored under $25^{\circ} \mathrm{C}$ and 65\% UR). Jaboticabal, UNESP, 2005.

\begin{tabular}{|c|c|c|c|c|c|c|c|c|}
\hline Fator & Luminosidade & Ângulo de cor & Cromaticidade & SS & AT & $\mathrm{pH}$ & Amido & CS \\
\hline \multicolumn{9}{|c|}{ Tipo de injúria } \\
\hline Controle & $38,79 \mathrm{~b}$ & $132,32 \mathrm{a}$ & $13,16 \mathrm{~b}$ & $4,70 a$ & $0,156 b$ & $6,14 a b$ & $0,297 a$ & $2,97 a$ \\
\hline Corte & 44,46 a & $130,40 \mathrm{a}$ & 19,07 a & $4,78 a$ & $0,173 a$ & $6,03 c$ & $0,286 a$ & $2,78 a$ \\
\hline Impacto & $45,90 \mathrm{a}$ & 132,23 a & $19,70 \mathrm{a}$ & $4,56 a$ & $0,173 a$ & $6,04 b c$ & $0,266 a$ & $3,02 a$ \\
\hline Compressão & 44,86 a & $130,41 \mathrm{a}$ & 19,42 a & $4,80 a$ & $0,145 b$ & $6,16 a$ & $0,239 a$ & $2,97 a$ \\
\hline DMS & 1,954 & 2,952 & 2,067 & 0,352 & 0,0271 & 0,112 & 0,097 & 0,438 \\
\hline \multicolumn{9}{|c|}{ Dia de armazenamento } \\
\hline 0 & 43,26 a & $131,39 a b$ & $18,53 \mathrm{a}$ & $3,73 d$ & $0,088 \mathrm{e}$ & $6,297 a$ & $0,415 a$ & $2,63 b$ \\
\hline 1 & $43,04 \mathrm{a}$ & $131,09 a b$ & $18,90 \mathrm{a}$ & $4,65 b c$ & $0,116 \mathrm{e}$ & $6,182 a b$ & - & $3,12 a b$ \\
\hline 3 & $42,91 \mathrm{a}$ & $129,93 a b$ & $17,66 \mathrm{a}$ & $5,48 a$ & $0,127 \mathrm{de}$ & $6,157 a b$ & $0,469 a$ & - \\
\hline 5 & $42,44 \mathrm{a}$ & $131,93 a b$ & $18,29 a$ & $4,70 \mathrm{bc}$ & $0,084 \mathrm{e}$ & $6,195 a b$ & - & $2,58 b$ \\
\hline 7 & $43,19 a$ & $134,52 \mathrm{a}$ & $16,32 \mathrm{a}$ & $5,02 a b c$ & $0,166 \mathrm{~cd}$ & $6,128 a b$ & $0,133 b$ & - \\
\hline 9 & $43,53 \mathrm{a}$ & $130,99 a b$ & $17,38 \mathrm{a}$ & $5,18 a b$ & $0,169 \mathrm{~cd}$ & $6,077 \mathrm{bc}$ & - & $3,39 a$ \\
\hline 11 & $44,55 \mathrm{a}$ & $132,15 a b$ & $17,54 \mathrm{a}$ & $4,52 c$ & $0,226 \mathrm{~b}$ & $5,882 \mathrm{c}$ & $0,242 b$ & - \\
\hline 13 & 44,50 a & $132,97 a b$ & $18,02 \mathrm{a}$ & $4,48 \mathrm{c}$ & $0,191 b c$ & $6,027 \mathrm{bc}$ & - & $2,68 b$ \\
\hline 15 & $44,46 \mathrm{a}$ & $128,73 \mathrm{~b}$ & $18,09 \mathrm{a}$ & $4,66 \mathrm{bc}$ & $0,281 a$ & $5,879 \mathrm{c}$ & $0,217 b$ & - \\
\hline DMS & 3,266 & 4,933 & 3,455 & 0,642 & 0,049 & 0,205 & 0,135 & 0,606 \\
\hline
\end{tabular}

$\mathrm{SS}=$ sólidos solúveis (soluble solids) ( ${ }^{\circ}$ Brix); $\mathrm{AT}=$ acidez titulável (titratable acidity) (g. de ácido cítrico.100 $\mathrm{mL}^{-1}$ ) (weight of citric acid in $\mathrm{g}$ $100 \mathrm{~mL}^{-1}$ ); Amido $($ starch $)=\mathrm{g}$ glicose $100 \mathrm{~g}$ de abobrinha (glicose weight in $100 \mathrm{~g}$ of green squash); $\mathrm{CS}=$ carboidratos solúveis (g.glicose.100g1) (soluble carbohidrates). Obs: Para cada variável, médias seguidas de pelo menos uma letra comum, na coluna, não diferem significativamente entre si, pelo teste de Tukey $(\mathrm{P}<0,05)$ (average values followed by the same letter in the column did not differ through the Tukey test, $5 \%)$.

recidos ou moles demais, início de podridões e polpa dura ou escurecida. Os frutos com coloração demasiadamente escura ou manchas enegrecidas, podridão aparente, muito murcho, casca enrugada, lesões e polpa escurecida, não apresentando condições de consumo, receberam nota 1 (péssima).

Foram efetuadas avaliações da coloração externa, em áreas pré-determinadas de frutos selecionados ao acaso em cada tratamento. Para esta, utilizou-se um colorímetro Minolta CR-200b, que determinava os valores de luminosidade (L), $a^{*}$ e b*. Esses resultados permitiram calcular o ângulo de cor (Hue) e a saturação da mesma (cromaticidade), conforme o recomendado pela Minolta Corp. (1994).

Para análises químicas, as amostras eram tomadas a cada três dias, comparando-se abobrinhas lesionadas e não lesionadas. As amostras foram analisadas, após serem trituradas, quanto aos seus conteúdos de acidez titulável (AT), sólidos solúveis (SS), teores de amido e de carboidratos solúveis (CS) (AOAC, 1997) e $\mathrm{pH}$.

A evolução da produção de $\mathrm{CO}_{2}$ foi determinada diariamente, colocando-se quatro frutos em recipiente com capa- cidade de 3 L (1 repetição), hermeticamente fechado, por um período de 1 hora, sob as condições de ambiente. Foram tomadas alíquotas de $0,3 \mathrm{~mL}$ do conteúdo da atmosfera do interior dos recipientes, antes e imediatamente após este período, com uma seringa apropriada (Exmire Microseringe, Ito Corp.), as quais tiveram seus teores de $\mathrm{CO}_{2}$ determinados em cromatógrafo (GC Finnigan 9001) equipado com detectores de condutividade térmica e de ionização de chama, assim como peneira molecular, metanador e coluna de aço inoxidável preenchida com Porapak N. As condições de trabalho foram: temperatura da coluna $55^{\circ} \mathrm{C}$, temperatura dos detectores $150^{\circ} \mathrm{C}$, temperatura do metanador $350^{\circ} \mathrm{C}$; fluxo de ar $175 \mathrm{~mL} \mathrm{~min}^{-1}$; fluxo de hidrogênio $15 \mathrm{~mL} \mathrm{~min}^{-1}$; e fluxo do nitrogênio $30 \mathrm{~mL} \mathrm{~min}^{-1}$. Os resultados para $\mathrm{O}_{2}$ e $\mathrm{CO}_{2}$ foram expressos em porcentagem, tendo como padrão uma mistura gasosa contendo $\mathrm{O}_{2}(10 \%), \mathrm{CO}_{2}$ $(0,11 \%)$, etileno (51 ppm) e $\mathrm{N}_{2}$ para completar $100 \%$.

Os dados obtidos foram submetidos à análise de variância por meio do teste $\mathrm{F}$, e as médias foram comparadas pelo teste de Tukey em nível de 5\% de pro- babilidade (SAS, 1999). A perda de massa fresca foi analisada comparandose a significância do paralelismo das retas pelo Teste T (Neter et al., 1978).

\section{RESULTADOS E DISCUSSÃO}

A maioria dos frutos do tratamento controle permaneceu com ótima aparência externa até o $13^{\circ}$ dia de armazenamento (Figura 1A). Os frutos do tratamento corte apresentaram grande resistência no local da injúria, formando uma "casca" endurecida (firmeza aproximada de $88,2 \mathrm{~N}$ ) o que prejudicou bastante a sua aparência. Os frutos submetidos ao impacto e à compressão se apresentaram mais amolecidos, principalmente no local da injúria. Esta região também se deteriorou mais rapidamente, prejudicando a aparência. Adicionalmente, nos frutos injuriados foi observada perda precoce do brilho e da turgidez característica. Com o passar dos dias de armazenamento (17 dias no total), estes frutos ficaram mais murchos que os intactos. Internamente, a maioria dos frutos do controle permaneceu com boa aparência por até nove dias após a colheita (Figura 1B). Entretanto, 
Tabela 2. Equações representativas da evolução da perda de massa fresca acumulada por abobrinhas verdes 'Caipira', submetidas a diferentes injúrias mecânicas e armazenadas a $25^{\circ} \mathrm{C}$ e $65 \%$ UR (Equations representative of the evolution of accumulated fresh mass lose from the green squash 'Caipira', submitted to various mechanical injuries and stored under $25^{\circ} \mathrm{C}$ and $65 \%$ UR). Jaboticabal, UNESP, 2005.

\begin{tabular}{llcc}
\hline Tratamentos & \multicolumn{1}{c}{$\mathbf{y}=\mathbf{a}+\mathbf{b x}^{\mathbf{a}}$} & $\mathbf{r}$ & Paralelismo $^{\mathbf{b}}$ \\
\hline Controle & $\mathrm{y}=365,85-4,3166 \mathrm{x}$ & $-0,9063^{* *}$ & $\mathrm{c}$ \\
Corte & $\mathrm{y}=384,82-4,5032 \mathrm{x}$ & $-0,9911^{* *}$ & $\mathrm{a}$ \\
Impacto & $\mathrm{y}=369,08-3,8860 \mathrm{x}$ & $-0,9931^{* *}$ & $\mathrm{~d}$ \\
Compressão & $\mathrm{y}=359,66-4,3345 \mathrm{x}$ & $-0,9931^{* *}$ & $\mathrm{~b}$ \\
\hline
\end{tabular}

${ }^{\mathrm{a}} \mathrm{y}=$ massa fresca $(\mathrm{g}) ; \mathrm{x}=$ tempo de armazenamento (dia); ${ }^{\mathrm{b}}$ retas seguidas de pelo menos uma letra comum, não diferem significativamente entre si, quanto ao teste $\mathrm{T}$ de paralelismo $\left({ }^{\mathrm{a}} \mathrm{y}=\right.$ fresh weight $(\mathrm{g}) ; \mathrm{x}=$ storing period (days); ${ }^{\mathrm{b}}$ average values followed by the same letter in the column did not differ through the paralelism $\mathrm{T}$ test).

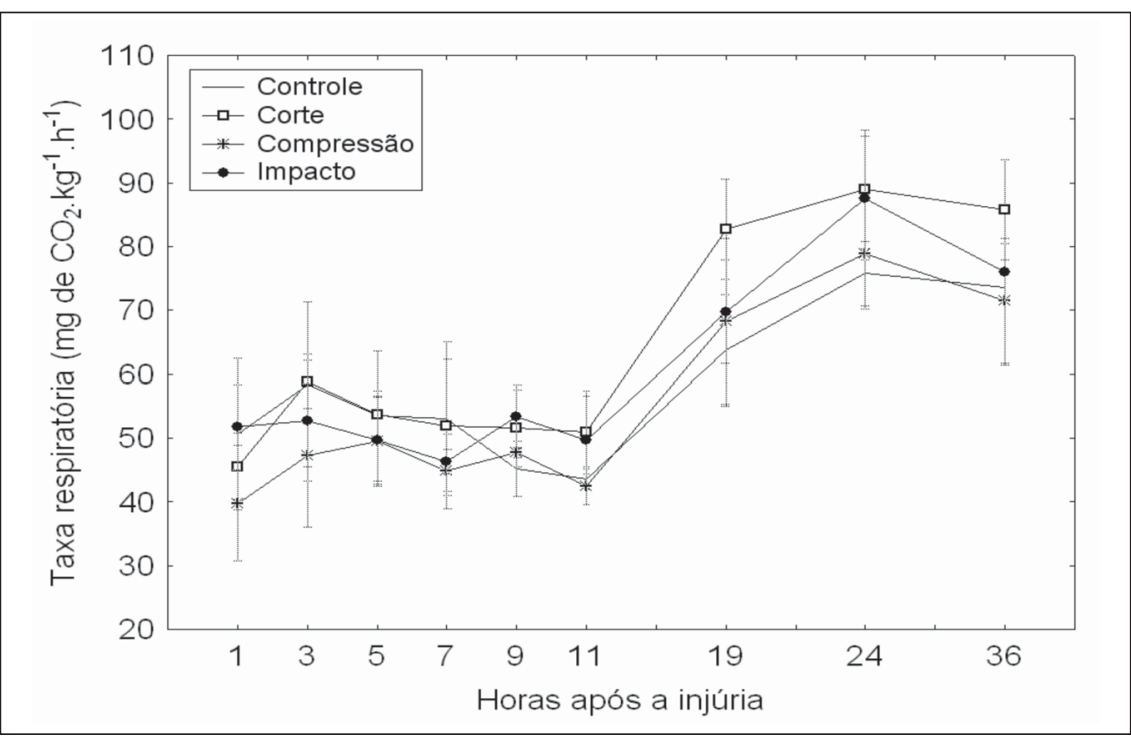

Figura 2. Evolução da atividade respiratória de abobrinhas 'Caipira' submetidas a diferentes injúrias mecânicas e armazenadas a $25^{\circ} \mathrm{C}$ e $65 \%$ UR. Barras verticais indicam o desvio padrão $(n=3)$ (Evolution of the respiratory activity of green squash 'Caipira' submitted to various mechanical injuries and stored under $25^{\circ} \mathrm{C}$ and $65 \%$ UR. Vertical bars indicate the standard deviation). Jaboticabal, UNESP, 2005.

com apenas um dia após as lesões, foi observado nos frutos do impacto, rachaduras na região das sementes, que resultou em amolecimento, no terceiro dia. No tratamento corte e compressão, observou-se um efeito contrário, com os frutos apresentando-se endurecidos e escurecidos, com algumas regiões translúcidas. No período avaliado, a injúria por corte promoveu as menores médias de aparência interna quando comparada aos demais tratamentos (em especial para coloração visual e índice de podridões).

As mudanças na coloração dos frutos foram significativas para luminosidade e cromaticidade, mostrando que as injúrias prejudicaram os fru- tos (Tabela 1). Foi observado escurecimento dos frutos dado pelo aumento nos valores de luminosidade e de cromaticidade, deixando o fruto verde escuro, não raramente com manchas marrons e/ou amarelo escuro. Este amarelecimento pode estar relacionado observado nas abobrinhas intactas com os dias de armazenamento, ou ao estresse, uma vez que se comparando regiões intactas e injuriadas dentro de um mesmo fruto houve maior amarelecimento nas regiões injuriadas, provavelmente devido ao desencadeamento da degradação da clorofila. ao amadurecimento, pois também foi
O corte e o impacto levaram a alterações nos valores de acidez titulável das abobrinhas. Apesar das diferenças entre os dias de armazenamento, houve uma estabilização para a maioria dos parâmetros químicos analisados (Tabela 1). O aumento da acidez e o decréscimo no pH são indicativos de provável aceleração do processo respiratório $(\mathrm{Ci}$ clo de Krebs) ou de solubilização das pectinas, o que torna o meio mais ácido. Foi constatado aumento nos teores de sólidos solúveis (SS) ao longo deste período. Estas modificações são evidenciadas também pela diminuição no conteúdo de amido ao longo do armazenamento. Mudanças nos teores de carboidratos incluem a conversão do amido a açúcares. A quebra de pectinas e outros polissacarídeos resultam em amaciamento dos produtos hortícolas e conseqüente aumento na suscetibilidade às injúrias mecânicas (Kader, 2002).

Verifica-se que os teores de carboidratos solúveis nos tratamentos e durante o armazenamento não diferiram significativamente entre si, o que também foi observado por Kasat (2004) em pêssegos 'Aurora-1'. Os carboidratos solúveis são constituídos, em sua quase totalidade por açúcares não redutores, com destaque para a sacarose. $\mathrm{O}$ teor de açúcares geralmente aumenta com o amadurecimento em frutos através de processos de biossíntese ou pela degradação de polissacarídeos e leva os valores médios a aumentos da ordem de $10 \%$ (Chitarra \& Chitarra, 1990).

Dentre as injúrias, a que levou à maior perda de massa ao longo do armazenamento foi o corte (Tabela 2). Nestes frutos, a injúria causada pelo corte facilitou a perda de água por transpiração devido ao rompimento das estruturas protetoras na casca. Segundo a porcentagem acumulada de perda de massa fresca, o corte foi o mais prejudicial totalizando $73 \%$, seguido da compressão que totalizou 72\% (Figura 2). Perdas de massa fresca também foram observadas por Hudson \& Orr (1977), ao estudarem a relação entre injúrias mecânicas por impacto e por abrasão, ou seja, que a perda de água em batatas foi maior naquela em que havia a ocorrência dessas injúrias. Verificaram ain$\mathrm{da}$, que lesões de $0,5 \mathrm{~cm}^{2}$ são capazes 
de dobrar a perda de água durante o armazenamento.

A atividade respiratória dos frutos foi pouco afetada após o lesionamento mecânico, durante as 36 horas em que foi monitorado (Tabela 2). Todos os frutos injuriados respiraram mais que os frutos intactos, com destaque para o corte, seguidos da compressão e impacto. Verificou-se que após a $11^{\mathrm{a}}$ hora houve incremento na atividade respiratória para todos os frutos injuriados, e tiveram um decréscimo após a $24^{\mathrm{a}}$ hora depois do início dos experimentos. Mattiuz \& Durigan (2001) também notaram para goiabas que os frutos injuriados produziram sempre maior quantidade de $\mathrm{CO}_{2}$ que os do controle, sem que se detectasse a ocorrência de pico respiratório.

Houve pequena diferença entre os tratamentos, apesar de não detectado pela estatística, onde a injúria por corte fez com que os frutos obtivessem as maiores medias de produção de $\mathrm{CO}_{2}$, demonstrando sua gravidade. A qualidade de abobrinhas 'Caipira' apresentou perda gradual de aparência e redução na vida útil intensificada pelos tratamentos corte e impacto. Houve evolução nos teores de acidez titulável e sólidos solúveis com diminuição nos valores de $\mathrm{pH}$ ao longo do período de armazenamento. O corte promoveu um aumento na perda de massa fresca acumulada e de atividade respiratória.

A qualidade das abobrinhas 'Caipira' sofreu perdas significativas durante o armazenamento em função das diferentes injúrias mecânicas, sendo que as injúrias por corte e impacto foram as que mais contribuíram para esta perda.

\section{AGRADECIMENTOS}

À FAPESP e à CAPES pelo auxílio financeiro.

\section{LITERATURA CITADA}

AOAC. 1997. Official methods of analysis of the Association of Official Analytical Chemists International. 16 ed. Washington: Ed. Patricia Cummiff, v.2, cap.37.

CHAU KV. 1997. Modified atmosphere packaging for fresh fruits and vegetables. In: CORTEZ LAB; NEVES FILHO LC. (Ed.) I Curso de atualização em tecnologia de resfriamento de frutas e hortaliças. Campinas: UNICAMP, $133 \mathrm{p}$.

CHITARRA MIF; CHITARRA AB. 1990. Póscolheita de frutos e hortaliças: fisiologia $\mathrm{e}$ manuseio. Lavras: FAEPE, 293p.

FILGUEIRA FAR. 2003. Novo manual de olericultura: Agrotecnologia moderna na produção e comercialização de hortaliças. 2 ed. Revista e ampliada. Viçosa: Universidade Federal de Viçosa, 412p.
HUDSON DE; ORR PH. 1977. Incidence of mechanical injuries to potatoes during certain storage-related handling operations in the River Valley production area. American Potato Journal 54: 11-21.

HYODO H; HASHIMOTO C; MOROZUMI S; UKAI M, YAMADA C. 1993. Induction of ethylene production and lignin formation in wounded mesocarp tissue of Cucurbita maxima L. Acta Horticulturae 343: 264-9.

ISHII G; CALBO AG; SILVA JLO. 1993. Effect of mechanical injury on ripeness and quality of mature green tomatoes. Annual Report from the Department of Applied Plant Physiology. Osaka: NIVOT, p.78-9.

KADER AA. 2002. Postharvest technology of horticultural crops. Oakland: University of California, Agriculture and Natural Resources, 535p.

KASAT GF. 2004. Efeito de injúrias mecânicas na qualidade pós-colheita de pêssegos Aurora-1. 47f. Monografia (Graduação em Agronomia) - Faculdade de Ciências Agrárias e Veterinárias, UNESP, Jaboticabal.

MATTIUZ BH; DURIGAN JF. 2001. Efeito de injúrias mecânicas no processo respiratório e nos parâmetros químicos de goiabas 'Paluma' e 'Pedro Sato'. Revista Brasileira de Fruticultura 23: 282-287.

MINOLTA CORP. 1994. Precise color communication: color control from feeling to instrumentation. Japão, 49 p.

NETER J; WASSERMAN W; WHITMORE GA. 1978. Applied linear statistical models. Massachussets: Allyn and Bacon, Inc. 745p.

SAS Institute Inc. 1999. SAS System for Microsoft Windows: release 8.02, Cary, NC, USA 